\title{
An evaluation of temperature stability and resistance in neonatal ventilator circuits
}

\author{
Jennifer A. Ruppert MPH, RRT, C-NPT ${ }^{1}$, Neil L. McNinch MS, RN, PSTAT ${ }^{\circledR 2}$, Teresa A. Volsko MBA, MHHS, RRT, CMTE, FAARC ${ }^{3}$
}

JA Ruppert, NL McNinch, TA Volsko. An evaluation of temperature stability and resistance in neonatal ventilator circuits. Can J Respir Ther 2021;57:8-13. doi: 10.29390/cjrt-2020-042.

\begin{abstract}
Background: Gas conditioning minimizes complications associated with invasive ventilation of neonates. Poorly conditioned gas contributes to humidity deficit, facilitates condensate pools, and contributes to safety events. The specific aim was to objectively quantify the temperature drop across the unheated portion of a neonatal circuit and the impact condensation has to resistance to flow in the ventilator circuit.

Methods: Ventilator circuits and filters were obtained, assembled according to manufacturer recommendations, and operational verification procedures were performed prior to data collection. A neonatal test lung was connected to each Servo-I ventilator with the following settings: pressure control IMV

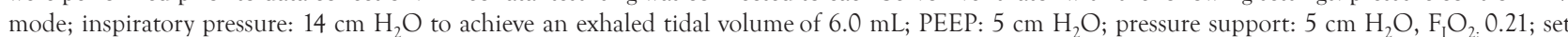
frequency $40 / \mathrm{min}$; and inspiratory time: $0.4 \mathrm{~s}$. The Fisher and Paykel MR850 and ChonchaTherm Neptune heaters were set at a temperature of $40^{\circ} \mathrm{C}$. To evaluate both systems under similar conditions, the ChonchaTherm Neptune heater humidity control was set to midline. Heaters were turned on simultaneously and given $1 \mathrm{~h}$ to equilibrate. Readings for room temperature, airway temperature at the patient connection, airway resistance, exhaled tidal volume, and direct observation of circuit condensation and (or) pooling were recorded hourly for a 48 -h period. Summary statistics were calculated for the variables of interest.

Results: Mean $( \pm \mathrm{SD})$ air temperature was $26.3^{\circ} \mathrm{C}( \pm 1.4)$ for the Fisher \& Paykel MR850 system and $26.2^{\circ} \mathrm{C}( \pm 1.5)$, for the ChonchaTherm Neptune system. Mean $( \pm \mathrm{SD})$ airway resistance was $229.3 \mathrm{~cm} \mathrm{H}_{2} \mathrm{O} / \mathrm{L} / \mathrm{s}( \pm 81.0)$ for the Fisher \& Paykel system and $196.2 \mathrm{~cm} \mathrm{H}_{2} \mathrm{O} / \mathrm{L} / \mathrm{s}( \pm 39.4)$ for the ChonchaTherm Neptune system. Mean $( \pm \mathrm{SD})$ tidal volume for the Fisher \& Paykel MR850 system was $6.5 \mathrm{~mL}( \pm 0.4)$, and for the ChonchaTherm Neptune system was $7.2 \mathrm{~mL}( \pm 0.6)$.

Conclusion: Circuit condensate increased tidal volume delivery and airway resistance. Temperature at the patient connection was lower than the temperature monitored by the system 12 inches distally, which can negatively impact gas conditioning.
\end{abstract}

Key Words: gas conditioning; condensate; humidification; temperature; neonatal ventilation; lavage

\section{INTRODUCTION}

It is important to condition inhaled gases by humidifying and heating the gas to body temperature to minimize complications associated with invasive mechanical ventilatory support of critically ill infants and children. Inadequate gas conditioning may lead to progressive airway dysfunction and systemic effects, depending on the degree of under-humidification and coolness, the exposure time, and the underlying disease [1]. Delivery of cooled (inspired temperatures less than $31.5^{\circ} \mathrm{C}$ ) humidified inspired gas can negatively affect the isothermal boundary and contribute to airway obstruction, bronchospasm, disruption of the bronchial epithelium, hypothermia, and redirected caloric intake $[2,3]$. Inadequately humidified gases delivered to intubated preterm infants can impair surfactant activity, decrease functional and residual capacity, and significantly compromise pulmonary mechanics [4].

Delivery of poorly conditioned gases increases the propensity for condensation pools to form in the ventilator circuit, which can increase resistance to flow through the circuit and the risk of accidental lavage. Adverse events due to accidental lavage from potentially contaminated circuit condensation include hypoxemia, microbial contamination of the lower airway, and life-threatening episodes of bradycardia requiring cardiopulmonary resuscitation [5].
The design of neonatal ventilator circuits differs from those used for adults and pediatric patients. Pediatric and adult heated wire ventilator circuits position the temperature probe near the patient connector and have the heated wires extend through the inspiratory limb. The temperature probe on neonatal circuits is distal to an unheated portion of tubing that attaches to the patient connector. The 12-inch segment of unheated corrugated tubing on the inspiratory limb of the circuit separates the temperature probe and remainder of the heated wire circuit from the patient connector. This 12-inch segment is needed to provide sufficient tubing length to position an infant or neonate in an incubator, or to facilitate kangaroo care (skin to skin holding with a caregiver). It also keeps the temperature probe away from the influence of the overhead heating element when a radiant warmer is used to maintain the infant or neonate's neutral thermal environment [6]. There is little published data on the effect the design of a neonatal circuit has on the delivery of inspired gas temperature, the condensate collection in the ventilator circuit, and the effect on the infant's resistive work of breathing.

The specific aim of this research was to objectively quantify the temperature drop across the unheated portion of a neonatal circuit and impact condensation has to resistance to flow in the ventilator circuit.

\footnotetext{
${ }^{1}$ Department of Respiratory Care, Akron Children's Hospital, Akron, OH, USA; ${ }^{2}$ Rebecca D. Considine Research Institute, Akron Children's Hospital, Akron, OH, USA; ${ }^{3}$ Department of Nursing Administration, Akron Children's Hospital, Akron, OH, USA

Correspondence: Jennifer A. Ruppert, MPS, RRT, C-NPT, Akron Children's Hospital, 1 Perkins Square, Akron, OH 44308, USA. Tel: (330) 543-3598, E-mail: jruppert@akronchildrens.org
}

Published online at https://www.cjrt.ca on 29 January 2021 


\section{METHODS}

Equipment preparation

The two different proprietary heater and ventilator circuits, commercially available for use in the United States, were tested in parallel. The Evaqua (Fisher \& Paykel Healthcare, Irvine, CA) and Hudson (Teleflex Medical, Research Triangle Park, NC) circuits were connected to proprietary heaters, Fisher \& Paykel MR850 and ChonchaTherm Neptune, respectively, and attached to a Servo-I Ventilator (Getinge, Inc., Wayne, NJ). An operational verification check, which includes a circuit tubing compliance check, was performed prior to the commencement of data collection. The ventilator parameters were representative of those reported in the literature during invasive ventilation of a preterm infant. The ventilator parameters [7] were adjusted with the intent of ventilating a premature infant weighing $1000 \mathrm{~g}$ (Table 1).

The NeoLung ${ }^{\circledR}$ (Ingmar Medical, Pittsburgh, PA), a neonatal test lung, was attached to each patient connection to maintain a closed circuit. The Fisher and Paykel MR850 heater and the ChonchaTherm Neptune were set to deliver a temperature of $40^{\circ} \mathrm{C}$. Since the Fisher and

\section{TABLE 1}

Ventilator settings used for the experimental design

\begin{tabular}{ll}
\hline Mode: & $\begin{array}{l}\text { Pressure control intermittent } \\
\text { mandatory ventilation }\end{array}$ \\
\hline Inspiratory pressure: & $14 \mathrm{~cm} \mathrm{H}_{2} \mathrm{O}$ (delivering an exhaled $\mathrm{V}_{\mathrm{T}}$ of \\
& approximately $6 \mathrm{~mL}$ ) \\
$\mathrm{PEEP}:$ & $5 \mathrm{~cm} \mathrm{H}_{2} \mathrm{O}$ \\
$\mathrm{F}_{1} \mathrm{O}_{2}:$ & 0.21 \\
Mandatory rate: & 40 breaths $/ \mathrm{min}$ \\
Inspiratory time: & $0.4 \mathrm{~s}$ \\
\hline
\end{tabular}

Paykel MR850 heater does not have humidity control, the humidity adjustment for the ChonchaTherm Neptune was set to midline. The heaters were turned on at the same time and given $1 \mathrm{~h}$ to equilibrate on the operator-set ventilator parameters prior to data collection.

\section{Data collection and analytical plan}

Hourly readings for room temperature, airway temperature, airway resistance, exhaled tidal volume, and direct observation of circuit condensation and (or) pooling were recorded for a 48-h period.

A digital thermometer was used to obtain room and airway temperature. The thermometer was then inserted in the ventilator circuit and placed proximal to the test lung at the patient connector prior to obtaining the reading.

Exhaled tidal volume and expiratory resistance values were obtained from each respective ventilator. The expiratory hold feature on the Servo-I was used to obtain airways resistance prior to draining circuit condensation. After noting the presence or absence of condensation in the circuit, the circuit was shaken and drained.

Data were collected and stored in Excel (Microsoft, Inc., Redmond, CA). Examination of the data included calculation of summary statistics for each of the variables of interest as well as graphical representation of temperature and resistance behavior over time by the creation of individual and moving range control charts (I-MR charts).

\section{RESULTS}

The two consecutively executed experiments resulted in 48 data points. The mean $( \pm \mathrm{SD})$ temperature of the room, in which this investigation was conducted was $22.1^{\circ} \mathrm{C}( \pm 1.2)$ with a full range of $20.4-24.8^{\circ} \mathrm{C}$. The mean $( \pm \mathrm{SD})$ air temperature was $26.3^{\circ} \mathrm{C}( \pm 1.4)$ for the Fisher \& Paykel MR850 system (Figure 1). The ChonchaTherm Neptune system

\section{FIGURE 1}

Individual and moving range chart displaying temperatures recorded hourly in ${ }^{\circ} \mathrm{C}$ using the Fisher and Paykel MR 850 heating system. Temperatures displayed in red with a black indicator marker above the datapoint represent those that exceeded the upper confidence limit.
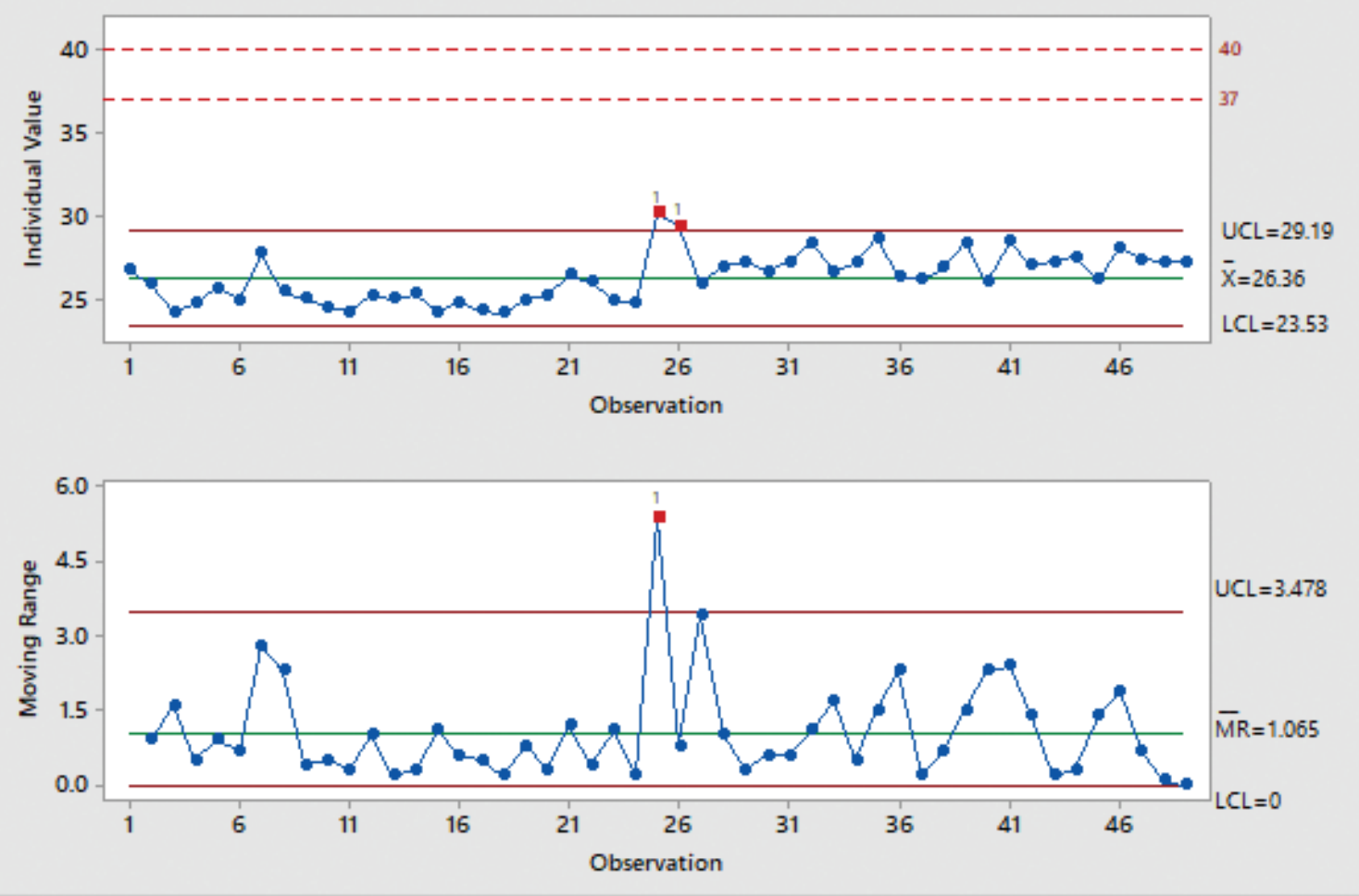
delivered a mean temperature $( \pm \mathrm{SD})$ of $26.2^{\circ} \mathrm{C}( \pm 1.5)$ (Figure 2). The mean $( \pm \mathrm{SD})$ airways resistance was $229.3 \mathrm{~cm} \mathrm{H} \mathrm{O} / \mathrm{L} / \mathrm{s}( \pm 81.0)$ for the Fisher \& Paykel MR580 system (Figure 3) and $196.2 \mathrm{~cm} \mathrm{H}_{2} \mathrm{O} / \mathrm{L} / \mathrm{s}$ $( \pm 39.4)$ for the ChonchaTherm Neptune system (Figure 4). The mean $( \pm$ SD) tidal volume for the Fisher \& Paykel system was $6.5 \mathrm{~mL}( \pm 0.4)$, and for the Hudson system was $7.2 \mathrm{~mL}( \pm 0.6)$. Raw data collected hourly for measured temperature and airway resistance are shown in Table 2.

I-MR charts were created for each system to facilitate review of behavior of temperature and air resistance over time. The Fisher \& Paykel MR850 temperature chart reveals that set temperature was not met during the experiment. There was one out-of-control point observed in the moving range and two in the individual chart. Also, there were two runs observed, one of 13 points below the mean and one of eight above in the individual chart, indicating shifts. No increasing or decreasing trends or astronomical points were noted. Airway resistance exhibited out-of-control points in the moving range (one point) and individual charts (two points). There were no shifts, trends, or astronomical points noted in the individual chart.

The temperature chart for the ChonchaTherm Neptune system shows that the set temperature was also not met during the course of the experiment. There were two out-of-control points observed in the moving range chart and 11 in the individual chart, indicating the process was not in control. In addition to being out of control there were two runs noted, one of 11 points above the mean and one consisting of 13 points below the mean in the individual chart, indicating shifts. No trends or astronomical points were noted. Airway resistance exhibited no outof-control points in either chart, nor were there runs, trends, or astronomical points noted in the individual chart.
Both systems exhibited lack of concordance with set temperature, shifts in temperature, and points of instability where processes were out of control temporarily, possibly indicating special cause variation of unknown source.

\section{DISCUSSION}

The bench test confirmed it was difficult to maintain satisfactory temperature, resulting in increased airway resistance and variations in tidal volume delivery. The delivery of adequately conditioned gases reduces the risk of airway occlusion, and reduces the risk of heat loss, insensible water loss, drying and thickening of bronchial secretions, cilia dysfunction, infection, airway plugging, bronchospasm, pneumothorax, and chronic lung disease [7]. Visual examination of I-MR charts (Figures 1 and 2) reveals the minimal variation in individual measures and moving ranges for airway temperatures delivered by the Fisher and Paykel MR 850 and ChonchaTherm Neptune systems, respectively. It is important to note that both systems delivered mean temperatures to the patient connection that were $11^{\circ} \mathrm{C}$ below the target temperature. Jardine, et al. [8] found that although there was a slight temperature drop from the set temperature of $40^{\circ} \mathrm{C}$ at the servo-controlled active heater, the target temperature of $37^{\circ} \mathrm{C}$ was attained at the proximal end of the endotracheal tube when the unheated portion of the ventilator circuit was removed. The 12-inch unheated section significantly reduces temperature delivery to the patient's artificial airway and subsequently lowers the absolute humidity [6]. This delivers inspired gas temperatures and humidity that is below the accepted standard of care for preterm infants requiring mechanical ventilatory support [9].

A relatively larger variability of air resistance was observed with the Fisher \& Paykel MR850 system compared with the ChonchaTherm

\section{FIGURE 2}

Individual and moving range chart displaying temperatures recorded hourly in ${ }^{\circ} \mathrm{C}$ using the ChonchaTherm Neptune heating system. Temperatures displayed in red with a black indicator marker above the datapoint represent those that exceeded the upper or lower confidence limits.
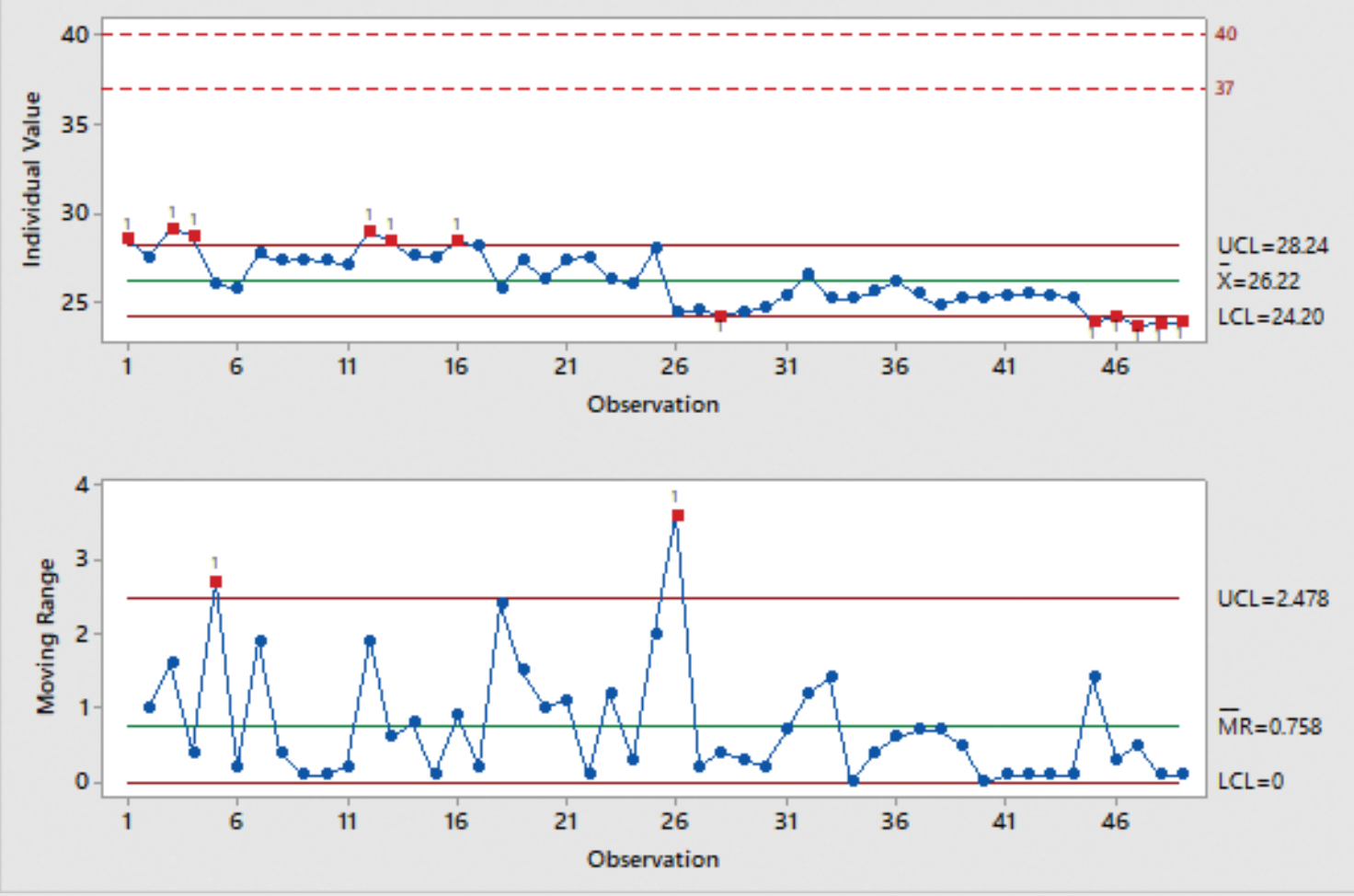


\section{FIGURE 3}

Individual and moving range chart displaying hourly airway resistance values, recorded in $\mathrm{cmH}_{2} \mathrm{O} / \mathrm{L} / \mathrm{s}$, using the Fisher and Paykel MR850 heating system. Values displayed in red with a black indicator marker above the datapoint represent those that exceeded the upper or lower confidence limits.
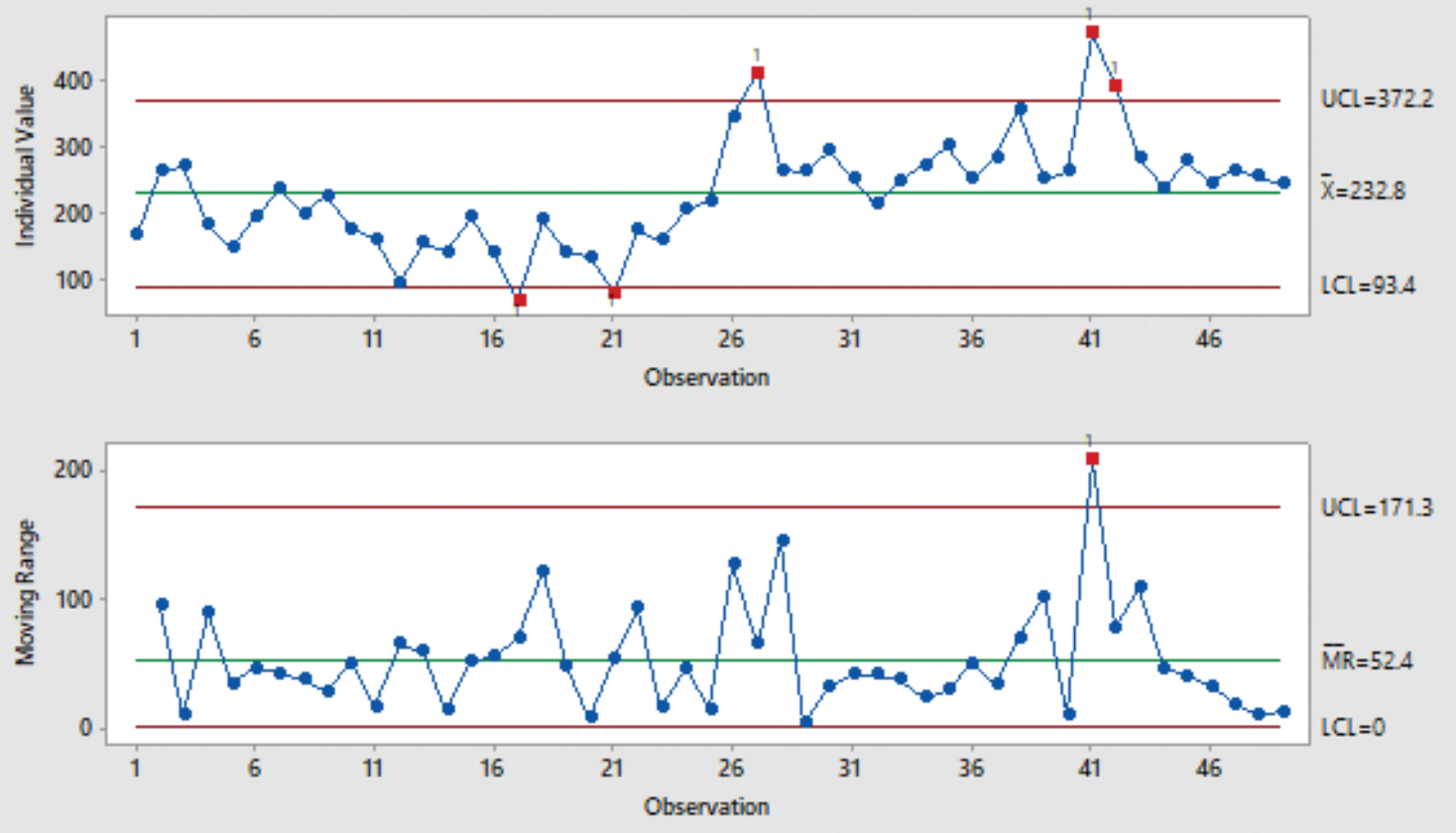

\section{FIGURE 4}

Individual and moving range chart displaying hourly airway resistance values, recorded in $\mathrm{cmH}_{2} \mathrm{O} / \mathrm{L} / \mathrm{s}$, using the ChonchaTherm Neptune heating system. Values displayed in red with a black indicator marker above the datapoint represent those that exceeded the upper confidence limit.
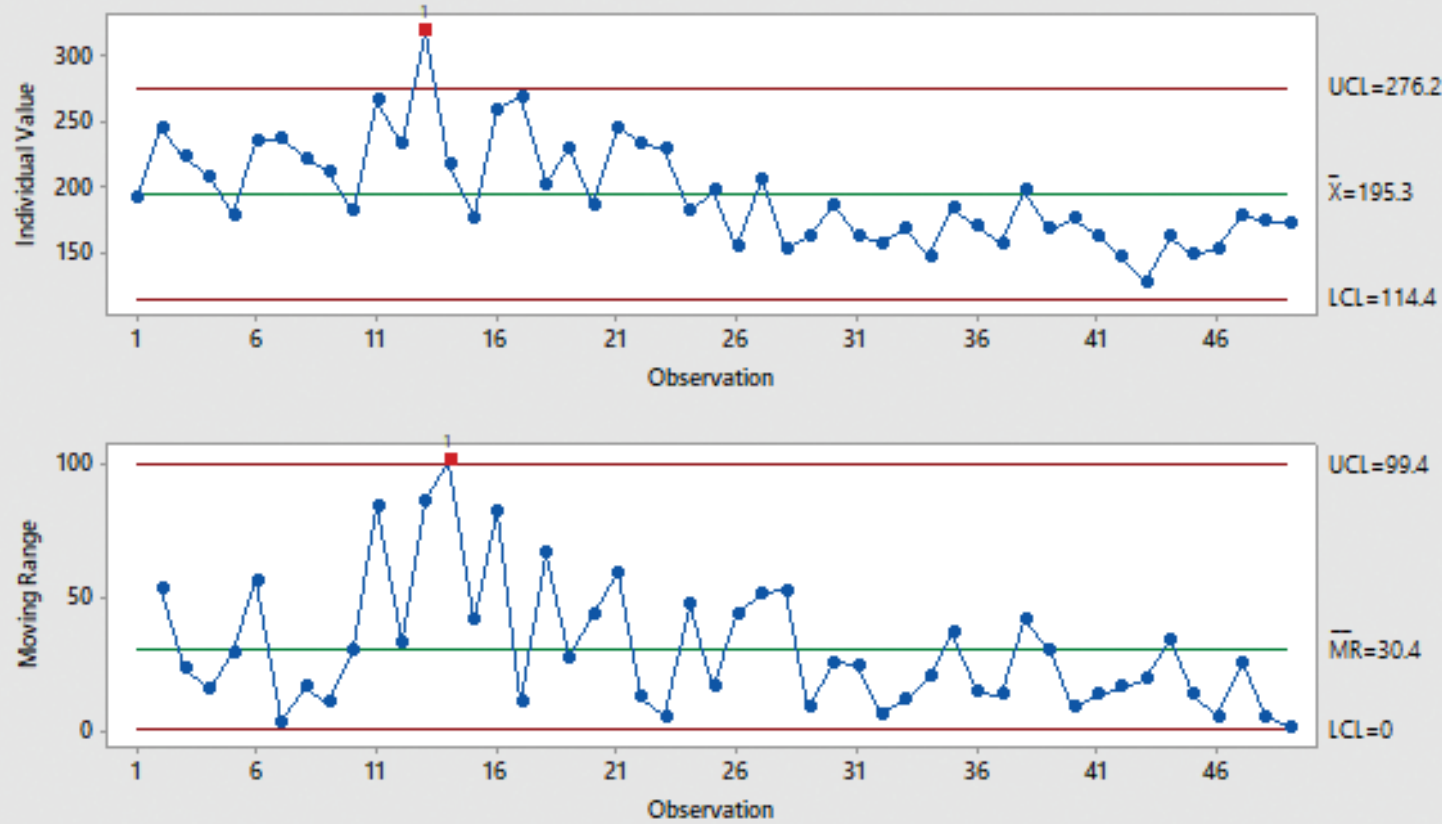
TABLE 2

Comparison of hourly readings for temperature, airway resistance and tidal volume for each of the active humidification systems used

\begin{tabular}{|c|c|c|c|c|c|c|}
\hline Hour & $\begin{array}{c}\text { The Fisher } \\
\text { and Paykel } \\
\text { MR850 recorded } \\
\text { temperature }\left({ }^{\circ} \mathrm{C}\right)\end{array}$ & $\begin{array}{l}\text { ChonchaTherm } \\
\text { Neptune recorded } \\
\text { temperature }\left({ }^{\circ} \mathrm{C}\right)\end{array}$ & $\begin{array}{l}\text { The Fisher and Paykel } \\
\text { MR850 recorded airway } \\
\text { resistance }\left(\mathrm{cm} \mathrm{H}_{2} \mathrm{O} / \mathrm{L} / \mathrm{s}\right)\end{array}$ & $\begin{array}{l}\text { ChonchaTherm } \\
\text { Neptune recorded } \\
\text { resistance (cm } \\
\left.\mathrm{H}_{2} \mathrm{O} / \mathrm{L} / \mathrm{s}\right)\end{array}$ & $\begin{array}{l}\text { The Fisher and } \\
\text { Paykel MR850 } \\
\text { exhaled tidal } \\
\text { volume (mL) }\end{array}$ & $\begin{array}{l}\text { ChonchaTherm } \\
\text { Neptune recorded } \\
\text { exhaled tidal } \\
\text { volume }(\mathrm{mL})\end{array}$ \\
\hline 1 & 26.8 & 28.5 & 170 & 193 & 7.3 & 8.4 \\
\hline 2 & 25.9 & 27.5 & 265 & 246 & 7.7 & 7.8 \\
\hline 3 & 24.3 & 29.1 & 274 & 223 & 7 & 7.8 \\
\hline 4 & 24.8 & 28.7 & 185 & 208 & 7 & 6.9 \\
\hline 5 & 25.7 & 26 & 151 & 179 & 6.7 & 7.1 \\
\hline 6 & 25 & 25.8 & 197 & 235 & 7.1 & 7 \\
\hline 7 & 27.8 & 27.7 & 239 & 238 & 7 & 7.4 \\
\hline 8 & 25.5 & 27.3 & 202 & 222 & 7.2 & 7.2 \\
\hline 9 & 25.1 & 27.4 & 230 & 212 & 7.1 & 6.3 \\
\hline 10 & 24.6 & 27.3 & 180 & 182 & 6.9 & 6.3 \\
\hline 11 & 24.3 & 27.1 & 164 & 266 & 6.4 & 6.8 \\
\hline 12 & 25.3 & 29 & 99 & 233 & 7 & 6.9 \\
\hline 13 & 25.1 & 28.4 & 158 & 319 & 6.7 & 6.2 \\
\hline 14 & 25.4 & 27.6 & 145 & 218 & 6.4 & 6.8 \\
\hline 15 & 24.3 & 27.5 & 197 & 177 & 6.6 & 5.8 \\
\hline 16 & 24.9 & 28.4 & 142 & 259 & 6.2 & 6.9 \\
\hline 17 & 24.4 & 28.2 & 72 & 269 & 6.5 & 6.7 \\
\hline 18 & 24.2 & 25.8 & 193 & 203 & 6.4 & 6.6 \\
\hline 19 & 25 & 27.3 & 145 & 230 & 6.5 & 6.5 \\
\hline 20 & 25.3 & 26.3 & 138 & 187 & 6.7 & 6.7 \\
\hline 21 & 26.5 & 27.4 & 84 & 246 & 6.2 & 6.4 \\
\hline 22 & 26.1 & 27.5 & 177 & 234 & 6.3 & 6.7 \\
\hline 23 & 25 & 26.3 & 162 & 229 & 6.1 & 6.7 \\
\hline 24 & 24.8 & 26 & 208 & 182 & 6.5 & 7 \\
\hline 25 & 30.2 & 28 & 222 & 198 & 6.2 & 6.5 \\
\hline 26 & 29.4 & 24.4 & 348 & 155 & 6.5 & 7.8 \\
\hline 27 & 26 & 24.6 & 413 & 206 & 6.2 & 7.3 \\
\hline 28 & 27 & 24.2 & 268 & 154 & 6.5 & 7.9 \\
\hline 29 & 27.3 & 24.5 & 265 & 162 & 6.6 & 7.8 \\
\hline 30 & 26.7 & 24.7 & 297 & 187 & 6.3 & 8 \\
\hline 31 & 27.3 & 25.4 & 256 & 163 & 6.2 & 7.9 \\
\hline 32 & 28.4 & 26.6 & 215 & 157 & 6.9 & 8.1 \\
\hline 33 & 26.7 & 25.2 & 252 & 168 & 6.2 & 7.7 \\
\hline 34 & 27.2 & 25.2 & 275 & 148 & 6.2 & 8 \\
\hline 35 & 28.7 & 25.6 & 304 & 184 & 6.7 & 7.9 \\
\hline 36 & 26.4 & 26.2 & 254 & 170 & 6.2 & 7.5 \\
\hline 37 & 26.2 & 25.5 & 287 & 157 & 6.9 & 6.9 \\
\hline 38 & 26.9 & 24.8 & 357 & 198 & 6.2 & 7.3 \\
\hline 39 & 28.4 & 25.3 & 255 & 168 & 6.3 & 7.4 \\
\hline 40 & 26.1 & 25.3 & 265 & 176 & 6.1 & 7.5 \\
\hline 41 & 28.5 & 25.4 & 473 & 163 & 6.4 & 8.4 \\
\hline 42 & 27.1 & 25.5 & 395 & 147 & 6.2 & 7.7 \\
\hline 43 & 27.3 & 25.4 & 287 & 128 & 6 & 8 \\
\hline 44 & 27.6 & 25.3 & 241 & 162 & 6.5 & 8 \\
\hline 45 & 26.2 & 23.9 & 281 & 149 & 6.3 & 7.8 \\
\hline 46 & 28.1 & 24.2 & 249 & 154 & 6.2 & 8.3 \\
\hline 47 & 27.4 & 23.7 & 267 & 179 & 6.8 & 7.3 \\
\hline 48 & 27.3 & 23.8 & 258 & 174 & 6.2 & 6.6 \\
\hline
\end{tabular}

Neptune. Mean and moving average values for airways resistance were higher for the Fisher \& Paykel system, and more variability in individual measures was noted. Differences in airway pressure may be attributed to circuit design. The Hudson system has a water collection trap incorporated into the expiratory limb of the circuit. The patient connector for the Fisher \& Paykel MR850 system is round and has a ridge or channel where the inspiratory and expiratory limbs attach. This design facilitated condensate collection, which is difficult to detect. Tidal volume delivery was also noted to be higher than the desired delivered tidal volume for both heating systems. The literature reports delivery of pressures higher than that set by the operator when condensate is noted in the expiratory limb of neonatal ventilator circuit [10]. Excessive pressure delivery contributes to higher than desired delivered tidal volumes that can compromise patient safety by over distending alveoli [11], impeding venous return, and causing hemodynamic instability [12].

Fluctuation in tidal volume $\left(\mathrm{V}_{\mathrm{T}}\right)$ seen with pressure control ventilation, may not have been as pronounced if a dual control or volume targeted mode of ventilation such as pressure regulated volume control ventilation were used. Although the use of dual control or volume targeted modes of ventilation provide a more stable tidal volume in the face of factors that impact pressure and tidal volume delivery such as endotrachial tube leaks, humidification, ventilator circuit compliance, and airway secretions, its use remains controversial in smaller infants, especially when the lung compliance of the patient is less than that of the ventilator circuit $[13,14]$.

Positioning of the ventilator circuit may have an impact on the changes in resistance and tidal volume delivery. Visual inspection of the 
Hudson circuit noted water accumulation in the water trap that, over time, changed the angle of the circuit, augmenting natural flow of excess condensation into the water trap. Since the Evaqua circuit, used with the Fisher and Paykel MR850 heater, did not have a water trap, condensation pools formed whose removal in the circuit was solely dependent upon physical draining at each hourly ventilator assessment. This difference in circuit design, allowing for natural condensation drainage, may have contributed to the lower airway resistance noted with the Hudson circuit and active heating system. The accumulation of condensate increases resistive loading of the infant respiratory system. The excessive respiratory muscle loading increases the infant's work of breathing, impairs gas exchange, and can increase ventilator length of stay [15]. Differences in ventilator circuit design are important for respiratory therapists to understand, so that quality improvement work can be developed and implemented to address problems associated with ventilator circuit design and improve care delivered at the bedside.

There were limitations of this laboratory investigation. The experimental design, specifically the use of different individuals assessing the amount of condensation and determining the need for draining the circuit, may have contributed to inconsistency in data collection. The inconsistencies that may have occurred with this experimental design mirror those that occur in clinical care. Evaluation of condensation in the circuit is very subjective, and although respiratory therapists may be trained in a uniform manner, subjectivity may still exist. Data collection also occurred over a brief period of time, $48 \mathrm{~h}$, which limited the numbered data points collected. It is difficult to determine whether extending the data collection period would have resulted in a different outcome.

A statistical comparison was precluded due to study design limitations: a comparison of summary measures violates independence, and there are not enough experimental iterations to conduct a repeated measures analysis.

\section{CONCLUSION}

Circuit condensate increased tidal volume delivery and airway resistance for the Fisher and Paykel 850 system. The temperature at the patient connection was lower than the temperature monitored by the system for both the Fisher and Paykel MR850 and the ChonchaTherm Neptune systems at the temperature probe positioned 12 inches distally. This has the potential to negatively impact gas conditioning. Understanding the impact of condensation and circuit design have on airway conditioning can assist respiratory therapists in determining the process used to properly care for the patient-ventilator circuit.

\section{Author's Contributions}

\section{DISCLOSURES}

The authors have read and confirmation that each author fulfilled the requirements of authorship as outlined in the instructors to authors for the Journal.

\section{Conflicts of Interest}

Jennifer Ruppert, Neil McNinch and Teresa Volsko disclose no conflicts of interest. Teresa Volsko discloses a relationship with Actuated Medical,
First Energy, and Prosperia in terms of grant funding for other research endeavors. She confirms, those relationships are unrelated to this research project or submission.

\section{Ethical Approval}

This laboratory investigation was submitted to and provided exempt status from the IRB.

\section{REFERENCES}

1. Schulze A. Respiratory gas conditioning and humidification. Clin Perinatol 2007;34(1):19-33. doi: 10.1016/i.clp.2006.12.009.

2. Sosulski R, Polin RA, Baumgart S. Respiratory water loss and heat balance in intubated infants receiving humidified air. J Pediatr 1983; 103(2):307-10. doi: 10.1016/S0022-3476(83)80374-6.

3. Plotnikow GA, Accoce M, Navarro E, Tiribelli N. Humidification and heating of inhaled gas in patients with artificial airway. A narrative review. Rev Bras Ter Intensiva 2018;30(1):86-97. doi: 10.5935/0103507X.20180015.

4. Tarnow-Mordi WO, Reid E, Griffiths P, Wilkinson AR. Low inspired gas temperature and respiratory complications in very low birth weight infants. J Pediatr 1989;114(3):438-42. doi: 10.1016/S0022-3476(89) 80567-0.

5. Schulze A. Respiratory gas conditioning in infants with an artificial airway. Semin Neonatol 2002;7(5):369-77. doi: 10.1053/siny.2002.0131.

6. Todd DA, Boyd J, Lloyd J, John E. Inspired gas humidity during mechanical ventilation: effects of humidification chamber, airway temperature probe position and environmental conditions. J Paediatr Child Health 2001;37(5):489-94. doi: 10.1046/j.1440-1754.2001.00750.x.

7. Brown MK, DiBlasi RM. Mechanical ventilation of the premature neonate Respir Care.2011;56(9):1298-311; discussion 1311-3. doi: 10.4187/ respcare.01429.

8. Jardine LA, Dunster KR, Davies MW. An experimental model for the measurement of inspired gas temperatures in ventilated neonates. Pediatr Pulmonol 2008;43(1):29-33. doi: 10.1002/ppul.20731.

9. te Pas AB, Lopriore E, Dito I, Morley CJ, Walther FJ. Humidified and heated air during stabilization at birth improves temperature in preterm infants. Pediatrics 2010;125(6):e1427-32. doi: 10.1542/peds.2009-2656.

10. Youngquest TM, Richardson CP, DiBlasi RM. Effects of condensate in the expiratory limb of neonatal circuits on airway pressure during bubble CPAP. Respir Care 2013;58(11):1840-46. doi: 10.4187/respcare.02322.

11. Shaffer TH, Koen PA, Moskowitz GD, Ferguson JD, DelivoriaPapadopoulos M. Positive end expiratory pressure: effects on lung mechanics of premature lambs. Biol Neonate 1978;34(1-2):1-10. doi: 10.1159/000241098.

12. Hobelmann Jr, CF, Smith DE, Virgilio RW, Peters RM. Mechanics of ventilation with positive end-expiratory pressure. Ann Thorac Surg 1977;24(1):68-76. doi: 10.1016/S0003-4975(10)64575-4.

13. Cannon ML, Cornell J, Tripp-Hamel DS, et al. Tidal volumes for ventilated infants should be determined with a pneumotachometer placed at the endotracheal tube. Am J Respir Crit Care Med 2000;162(6):2109-12. doi: 10.1164/ajrccm.162.6.9906112.

14. Heulitt MJ, Holt SJ, Thurman TL, Hall RA, Jo CH, Simpson P. Reliability of measured tidal volume in mechanically ventilated young pigs with normal lungs. Intensive Care Med 2005;31(9):1255-61. doi: $10.1007 / \mathrm{s} 00134-005-2717-\mathrm{y}$.

15. Isono S, Nishino T, Sugimori K, Mizuguchi T. Respiratory effects of expiratory flow-resistive loading in conscious and anesthetized humans. Anesth Analg 1990;70(6):594-9. doi: 10.1213/00000539-19900600000004 . 